\title{
Emergency Remote Teaching in Higher Education During Covid-19:
}

\section{Challenges and Opportunities}

\author{
Nokukhanya $\mathrm{N} \mathrm{Jili}^{1}$, Chuks I Ede ${ }^{1} \&$ Mfundo Mandla Masuku ${ }^{2}$ \\ ${ }^{1}$ Department of Public Administration, Faculty of Commerce, Administration and Law, University of Zululand, \\ South Africa \\ ${ }^{2}$ School of Development Studies, Faculty of Economics, Development and Business Sciences, University of \\ Mpumalanga, South Africa \\ Correspondence: Mfundo Mandla Masuku, School of Development Studies, Faculty of Economics, Development \\ and Business Sciences, University of Mpumalanga, South Africa.
}

Received: November 26, 2020

Accepted: April 1, 2021

Online Published: April 1, 2021

doi:10.5430/ijhe.v10n5p1

URL: https://doi.org/10.5430/ijhe.v10n5p1

\begin{abstract}
The third quarter of 2020 marks the closure of on-campus face-to-face pedagogies in South Africa's institutions of higher learning due to Coronavirus disease (COVID-19). The need to maintain social distancing necessitated the transition to emergency remote teaching. A few institutions of higher learnings could move their classes effectively to online and distance education platforms because of their pre-existing experience and some grapple with managing the 'new normal'. This article reflects on the challenges and opportunities of an emergency remote teaching in institutions of higher learnings during the COVID-19 pandemic. The article adopted a qualitative approach through relevant literature and policy reviews to critically analyse emergency remote teaching during the era of COVID-19. The findings indicate that some staff and students experience challenges related to the lack of resources and exposure to remotely use information and communication technology. The article acclaims that institutions of higher learnings should acquire suitable information and communication technology equipment and develop the requisite facilities, implement rules and regulations for their availability, and adequate maintenance. This recommends promoting technologically compliant ethics within the institution, provide easy access to teaching and learning by both students and academic staff at an affordable and fixed (secure) cost in safe, conducive, and unrestricted environments for students.
\end{abstract}

Keywords: emergency remote teaching, institutions of higher learning, COVID-19, information and communication technology

\section{Introduction}

The mélange of globalisation and technological development turned the world into a global village. Individuals can accomplish various tasks from most parts of the world using technological devices. Technological development ushered overwhelming upshots, and these know no bounds, defying all geographical partitions, as their dividends are increasingly timeless (Nevado Peña et al., 2020). Prominent amongst these outcomes and dividends is the invention of technological infrastructure that supports education at the open or remote level. Education has stood out as a distinguishing factor amongst humankind and other kinds of living organisms. It is often regarded as human's most essential right as living beings (owing to its significance to the psychological and socio-economic development of the human race).

It was adjudged as the most valuable knowledge or skills-acquisition process effectively used by humans. It revolutionises the way individuals live, think, and do things. South Africa's first democratically elected President, Nelson Mandela described education as the most powerful device that humans can employ to change the world (Strauss, 2013). Whilst others observe it as a form of "light" or "enlightener", we describe it as the purveyor of purposeful facts for humankind's informed evolution and optimal livelihood.

In developing countries, education has often come under dire trials especially in events of unforeseen circumstances where even our mobility and existence as humans are seriously endangered (Alcázar et al., 2020). Circumstances, 
such as COVID-19 induced lockdown, created an emergency, shifting the focus on survival. This creates an opportunity for socio-economic pursuits such as education, to be neglected. Globally, humans' predominant thoughts and concerns focused on health, wellbeing and recuperating in the event of COVID-19 infection vis-à-vis thinking about where they kept their schoolbags and schoolbooks during the lockdown period.

In a situation where lockdown restrictions on human movements and institutional functioning are unduly prolonged on health grounds, the consequences of our overall psychological wellbeing become a priority. Therefore, the pursuit of such socio-economic activities as formal education during the COVID-19 pandemic remains a legitimate attempt. To achieve this, the use of scientific and technological innovations supporting unrestricted education especially at a higher level is a sustainable alternative. The United Nations' (UN) Articles 26 and 27 assert the righthood of education for everyone's right to benefit from the "scientific [and technological] advancement" "of the community" or country of residence. Although this comes with several opportunities, the challenges often make these opportunities difficult to realise owing to various overbearing factors.

Provided the ease of access to information precipitated by the internet, teaching and learning can be facilitated through emergency remote teaching (ERT) and interaction between students and lecturers. This interaction could enhance teaching, research skills, learning and communication, which can be facilitated online. This article examines the opportunities, benefits, implications, and challenges of using technology in higher education during the COVID-19 pandemic. The report employs a critical review of the literature to explore ERT challenges and opportunities in higher education. The article also reflects on how to mitigate the various challenges impinging on ERT in higher education.

\section{Conceptualising Remote Teaching and Learning}

The concept of "emergency remote teaching" was described as a temporary instructional responsive teaching to the crisis, differing from pre-planned online learning (Whittle et al., 2020). ERT is referred as unexpected short-term instructional delivery to an online delivery model because of a mammoth catastrophe, in contrary to the online academic programmes originally planned and designated to be delivered virtually (Hodges et al., 2020). Further, Blessinger and Bliss (2016) contend that remote teaching means to be "flexible, free, and welcoming, non-prejudiced, non-restricted and unfettered".

Open education, as an alternative to the real-place transmission of instructional content, allows individuals to access and participate in education regardless of their physical/geographic location, provided they have the means (computer, smartphone, internet) to connect to the resources (Blessinger and Bliss, 2016; Tsabedze and Ngoepe, 2020). Whether ERT is conceptualised as open learning, online learning, distance education, based on respective individual or institutional perception, this phenomenon enhances unlimited and unrestricted access to all students to meet their higher education needs, not within the four walls of institutions, but the comfort of their homes and their nearest library.

The word "remote" was derived from the Latin word removere, which transmuted to remotus, to mean "move away or move back" or simply "removed". In its basic form, "remote" therefore implies far-flung (or far afield), isolated and distant (from the actual source or epicentre) (Harms et al., 2014). ERT, therefore, entails delivering curricular contents, instructional material or educational resources to the target learning audience physically away from the centre or institution of learning. Emergency remote teaching during COVID-19 became exceptionally inevitable in areas with the most difficult terrain where physical access to educational centres and resources is hampered.

Furthermore, ERT is a feasible alternative amongst learning students unconventionally dispersed, either locally or abroad, with limited contact to educational facilities and instructional materials for their learning needs. Emergency remote teaching is the transmission of curricular contents, which deemphasises person-to-person contact. This contact involves both educators and learners, therefore, it is transmitted overboard beyond the limit of space or number through an online medium (employing electronic networks and devices) and/or through correspondence, promoting interactive scholarship at the most efficient and realisable rate. Globally, the emergency posed by COVID-19 popularised ERT as a temporary intervention to complete a higher education academic year.

\section{Discourses on the Need for Covid-19 Induced Emergency Remote Teaching}

The debate on the right to education for all attracted much attention from various stakeholders and scholars who either contend in support of or are against the provisions of the UN's Article 26 (Sub-articles 1, 2 and 3) and Sub-article 1 of 27. According to UN's Articles 26(1-3) and 27(1) "everyone has the right to education ... and higher education shall be equally accessible to all", [as] "everyone has the right freely ... to share in scientific advancement" [of the community] or country of residence "and its benefits". Based on keen observation of the scripted sequence of 
both articles' provisions, it is presumed that even the United Nations is cognisant of the salient link between education and scientific/technological advancement. Provided that ERT benefits can be effectively maximised through information and communication technology (ICT), the reality of accessible higher education and scientific (or technological) development during the COVID-19 induced lockdown is a moral imperative.

Globally, COVID-19 induced lockdowns affecting "more than 1.5 billion students of all ages due to schools and universities closures" (Bozkurt and Sharma, 2020: 1). That whopping figure is slightly over 20\% of the global human population, although the affected students account for "around $90 \%$ of the world's enrolled students" (Bozkurt and Sharma, 2020). The implications of this educational emergency on both the psychological and socioeconomic wellbeing of students, teachers and broader society are better imagined than inscribed. Aside from the abrupt cessation to all activities and actors involved in public and private institutions of higher learnings (IHL), the overly mental inactivity resulting from these students' shift of focus from their studies may have contributed significantly to the rising global mental health concerns, especially concerning anxiety disorders and depressive tendencies (Power et al., 2020).

The consequence of depriving many people (comparable to $80 \%$ of Africa's entire human population) of their right to education also generated more concern with "no shortage of calls for evidence-based and pragmatic approaches to ERT" (Aguliera and Nightengale-Lee, 2020: 2). These are required to salvage the already desolated academic year and the affected learning publics therein. Such as equalising idea, aiming at restoring evenness and well-adjusted access to education amidst the pandemic emergency, constitutes the theoretical work (Burde et al., 2017). The authors focus on crisis-prone emergencies, as against that of contemporary global pandemic, its theoretical relevance is as just more explicable due to the proportional spread to nearly a quarter of the global population, or two billion people which quantifies their own emergency as a real global emergency predicament equally proportionate to a pandemic. Burde et al. (2017: 620) contend that since education was a part of the global humanitarian response to emergencies "at least since the 1950s", why then is it not included in the pandemic-induced global emergency? Their verdict:

\begin{abstract}
"In the midst of an emergency, when a state bureaucracy is weak or absent, non-state actors such as United Nations (UN) agencies and other international or local nongovernmental organisations often support educational interventions. For example, they may support schools in communities where state services were broken down or provide supplementary educational activities that are intended to protect children from harm and to promote cognitive, emotional, and social development" (Sinclair, 2002: 23).
\end{abstract}

Education is an essential service required during an emergency, and "from the realisation that millions" of students are usually affected as "they often lack access to education"; any attempt to undermine this right is tantamount to gross insensitivity and sabotage on the part of the government (Burde et al., 2017; Karalis, 2020). This is because of the belief that uneducated masses (like their hungry counterparts) may contribute to instability or fragility in weak states or countries. Aid to education can stabilise these countries, enhance state-building efforts, and promote global security (Burde et al., 2017). They, therefore, advocate for an educational relief support package as part of "other forms of relief aid" for the masses in countries under emergency, to keep their mind and body together in the way social and economic palliative measures would do with their lives and livelihoods.

Burde et al. (2011) contend that "education in emergency theory" separates education from normal development activities to being incorporated into traditional humanitarian assistance, on the discernment that such emergencies usually signal its urgency and underscore its relevance to the "humanitarian response paradigm". Further, they opine that this global attempt emphasises on delivering education as an essential service that could be packaged (like United Nation's Children Emergency Fund's "School Box" program); it emphasises its compatibility with other forms of packaged emergency aid with core humanitarian principles (Burde et al., 2017: 622). They, therefore, restate the urgent need for education to gain support as a humanitarian need and a human right, whilst recommending strategies for their advancement, especially through ERT instrumentality (Burde et al. 2017). Furthermore, Savani et al. (2017) question the fundamental righthood of education for all, advancing their argument with "people's lay theories" explaining how humankind's intellectual potential drives their positions on education. The authors contend that lay theories are people's naïve assumptions about distinctive characteristics. Therefore, people's lay theories about intellectual potential refer to their beliefs about the distribution of intellectual potential (the capacity to exhibit high intelligence) across the population. Whereas some express this belief universally that most individuals have high intellectual potential, others hold a non-universal opinion that only some people have high intellectual potential (Savani et al., 2017: 3). The authors propose that a way to balance these conflicting beliefs is by identifying and 
understanding the variance amongst each party's beliefs, from when they settle universal beliefs, in either way influence the way people observe education as a fundamental human right. Consequently, the probability of their corresponding policy attitude following this understanding of education will be high.

Savani et al. (2017) contend that this conviction has the potential to spur government and the people to support institutions that can help deliver this right. For instance, by accepting the reality of remote teaching and learning par opposition to the traditional mode of real-place higher education and acquiring appropriate technological devices for their ERT needs whilst adopting proper ICT-compliant attitudes. These should correspond with an appropriate mindset and maintenance culture and adequate means to both services and preserve their ICT-powered ERT despite their geographical locations. Often, the affected masses would naturally fight for and defend their right to higher education; in the same way, they struggle or fight for social relief supplies and economic palliative measures for their physiological and economic needs. The critical question is whether South African masses have come to terms with this reality. The situation in South Africa puts students in an obscure position regarding remote teaching and learning higher education as their voices are yet to be heard.

Gillies (2015:1) Human Capital Theory (HCT) in Education lays considerable stress on the education of individuals as the main means by which both the individual accrues advantage material, by which the economy progresses. The theory acknowledges the unpredictability of emergencies and their potentially lethal effect on the economic scenery at both individual and state levels whilst advocating for education as the sole catalyst for resuscitating the economy at all levels owing to its capital value on the individual with ripple effects on the national economy.

Gillies (2015:1) maintains that HCT promotes education as a crucial instrumental role in boosting economic growth, which many emergency-ridden economies would naturally require at this time, on his theoretical finding that workforce is more qualitative than quantitative. This makes education and training the most important ways where the quality of the workforce could be enhanced (Gillies 2015: 2). Its process, therefore, should ideally not be disrupted. Conversely, an attempt to disrupt the education process during an emergency is synonymous to the condition of a terminally ill patient who refuses to adhere to helpful medications. Patton (2016) argues that this disruption existed historically on racial grounds.

Prehistorical evidence of transatlantic trade prompted Western institutions' development, which invariably enabled their financial stability on cheap labour provided by the slaves (Patton, 2016). As a result, those institutions, such as IHL, continued to advance cheap labour with which they maintained their schools and faculties as the intellectual and cultural playgrounds of the plantation and merchant elite (Patton, 2016: 318). The author further contends that historically institutionalised racial inequalities continue to affect higher education sector in many developing countries, such that any arising emergency at either global or regional level would predictably expose this endemic, historically entrenched inequality. The miserly approach to staffing by many IHL to their insensitivity to the training and retraining needs of their staff. This global pandemic exposed a significant divergence in teacher preparation and training for ERT, including technology teaching to ensure continuity of learning for students at a distance (Whalen, 2020).

Whalen (2020: 190-191) attests to his amazement that most of the participants never attempted ERT [or] online teaching before, therefore, they felt overwhelmed and unprepared to use online or remote teaching strategies and devices [and] struggled to adapt their pedagogy to fluctuating situations. Although his study was conducted in America (yet with such a dissatisfactory finding), we fear that a more distressful situation amongst SA's IHL might be imminent.

Whalen (2020: 190) states in allusion to Hodges (2020: 5) that the continued closure of universities due to the outbreak of COVID-19 is a direct contrast of the evidence from the United States Department of Education (1996) that technologically enabled in-person, distance and remote teaching occurred since the early 1980s. In South Africa, protests-induced university shutdowns have from 2015 to 2017, compelled senior decision-makers to announce blended learning as a strategy to enable students to complete their courses to enhance successful completion of the academic year. The digital divide, social inequalities, political and people's factors, and the indifferent disposition by the private sector partners, are the main challenges why any benefit of a remote teaching in South Africa would end up as a mirage (Czerniewicz, 2020).

\section{Methodology}

The qualitative approach was used in this report to critically review the relevant literature, specifically on the effectiveness of ERT in higher education during COVID-19 pandemic in South Africa. A criterion-based sampling method was employed to select South African and global literature on the pandemic and its effect in South African 
higher education. Some articles on e-learning and technology in higher education were used as a source of reference, which was published before the pandemic. Therefore, the literature was selected from research databases including Google Scholar and Emerald Insight Journals. The authors used search words, such as "COVID-19 and high education in South Africa or COVID-19 and emergency remote teaching in higher education".

All selected secondary sources were screened by title, abstract and full text. South African literature on COVID-19 in higher education is amongst few sources that examine the effects of a pandemic on the effectiveness of teaching and learning during the pandemic. South African literature revealed a series of challenges in the higher education sector's response to the COVID-19 crisis. This exposed the weaknesses of the sector to fully integrate technology in teaching and learning. Therefore, the issue of a lack of technological teaching and learning devices during the pandemic gaining significant attention.

\section{Results and Discussion}

In this section, findings from the reviewed literature are critically discussed.

\subsection{Derivable Benefits of Emergency Remote Teaching for Institutions of Higher Learnings in South Africa}

The benefits of ERT are inexhaustive. This article posits that these will be most realisable in South Africa where recent upheavals indicate that the only sustainable alternative for the protests-plagued higher education sector might be ERT. The idea of ERT signifies open, unrestricted, and liberated tuition; it envisages intellectual autonomy with far-reaching implications on the social, economic, physical, and institutional developments both students and lecturers (Toquero and Talidong, 2020). The primary benefit of ERT is social coexistence and cohesion. ERT promotes peaceful coexistence and harmony between IHL and students who would comfortably study from home or at least away from campus where their chances of participation in the social rivalry will be barely present, as they will be united with their families and perpetually be under their watchful eyes. The rate of social injustice and moral decadence on campus could drop abruptly; therefore, the institutional image of higher institutions will be sustained. Essentially, ERT reduces the financial burden of hostel accommodation with related costs (maintenance, transportation, provisions, etc) for students. It also reduces teaching and administrative costs for IHL.

The quality of higher education will be upheld through ERT. Students will be studying at their own pace and their lecturers will have limited physical contact with them, which invariably reduces incidents of abuses, blackmail, exploitation, and gender-based violence. ERT emphasises academic meritocracy and students' performance as opposed to the traditional physical class system where each learner's survival is tempered in collective friction and degenerated by bullying, equal to a survival-of-the-fittest scenario (Hodges, 2020). Marginal costs of a real-place class system, including interpersonal complications, students' unhealthy politicking at the expense of their studies, cliques and nonconformist, campus gangsterism and occultism, are non-occurrent in ERT mode of higher education.

The shift to ERT significantly promotes healthy academic competition amongst students with no social or physical cost. ERT, therefore, ensures learners' responsibility by placing them in control of their studies with their academic and professional destiny in their own hands. The concern of safeguarding students' religious rights at the cost of their main mission on campus, with its associated consequences, such as religious extremism, religious intolerance and spiritual radicality will no longer be campus occurrences. Conversely, ERT enhances access to higher education since concerns of controlled students' enrolments attributable to limited space in classrooms and hostel accommodation will now be history. We envisage that the shift to remote teaching (RT) will dovetail into government policy of open higher education for all South Africans. Further, adopting RT complies with the United Nations' policy on accessible higher education for all.

\subsection{Factors Overbearing the Operation and Efficacy of Emergency Remote Teaching in South Africa}

South Africa's higher education sector (HES) comprises all IHL, public and private research institutions, regulatory agencies and professional bodies. HES also comprises stakeholders, such as researchers/students, academic and non-academic staff, and those involved in the creation, preservation, provision, transmission, delivery of curricular contents and instructional material. These stakeholders advance post-secondary learning with their assessments for higher institutional or individual (private) learning (Ifenthaler and Yau, 2019; Achhnani, 2019). The processes of each HES' component depend on their internal compositions and capacity within contending factors by which it is made or marred at varying effects. These factors are classified into internal and external. Internal comprises psychological (individual) or managerial (institutional) levels, determining how well each component operates. External includes the political, socioeconomic, cultural, technological, and geographical, determining the longevity of such operation (Czerniewicz et al., 202).

Although the merits of ERT are enormous, the optimisation of its benefits is limited to the interplay of numerous 
factors. The effectiveness of ERT in advanced countries, therefore, varies significantly from their developing or underdeveloped counterparts. This further explains the variance in individuals' and higher education's institutional performance concerning ERT, and that of higher education sectors (in various countries). Similarly, the performance of students from technologically disadvantaged nations differs upon their transfer to technologically advanced countries or any IHL with adequate facilities to enhance ERT. Therefore, the following factors determine the effectiveness of ERT in South Africa:

\subsubsection{The Technological Base}

The degree at which South Africa advances ERT supporting technology within its frontiers, the more or less likely it maximises the dividends for the learning publics (Adedoyin and Soykan, 2020). The country's technological base encompasses the presence or reality of scientific artefacts and advanced technological infrastructure, equipment, and the requisite gadgets for the automated operations of both public and private educational activities and processes. The technological revolution opposes manual operations emphasising mechanisation by employing hi-tech devices for the day-to-day running of tasks. To realise the efficacy of ERT in South Africa, ICT innovations enabling students to study without borders must be developed and implemented to promote boundless dissemination of curricular information and instructional material.

This would facilitate communication between lecturers and students, promoting a more interactive tuition process. The latest policy to promote extensive deregulation in the digital communication technology sector in South Africa, which provides ICT companies unrestricted right to deploy 5G ICT infrastructures in every part of South Africa, ascribes enormous regards to the progress in the Department of Communications and Digital Technologies (Gallagher, 2019; Corrigan, 2020). The clause sharing the right to private property with ICT companies might be the policy's weakness and the cause of disagreement, due to fears of clashes between ICT companies and private landowners (Shulman, 2020). There is a risk of vandalisation of such ICT infrastructure and facilities, which may resultantly interrupt the ERT needs of scholars in the affected areas.

\subsubsection{The Political and Administrative Climate in South Africa}

The government did not prioritise the administration of ERT during COVID-19. The focus was on offering the generalised schemes of employment protection observed in the wider economy (Brammer and Clark, 2020). Apart from controlling state power at various levels, the political system should ensure that state resources are effectively managed for the fair improvement of both the state and its citizens. The political and administrative systems should promote an open system, receptive and interactive to modern trends in innovation and technological developments, by rendering vital concepts into acquiescent policies that will advance ICT within its frontiers. Therefore, the import of technological-friendly policies, programmes, and projects, facilitating ERT, cannot be overstressed. It is envisaged that these will help impart a corresponding culture in the citizenry.

\subsubsection{Psychocultural Factor}

The psycho-cultural factor encompasses beliefs, thinking, values and ethos (character, code of behaviour, attitude), as "culture" is exclusively recognised as the manner of life and existence of people in a place. The policies crafted by the political and administrative systems in the state play a crucial role by governing the affairs and conduct of both state and citizens at all public and in most private fronts (Asongu and Le Roux, 2016). The South African government can implement good policies compliant with the latest trends in innovation and technological development to promote ERT for all students eligible for higher education. It further requires a positive and ICT-friendly attitude from them, for a consistent technologically advancing and learning society (Asongu and Le Roux, 2016). The masses too can imbibe a positive mindset towards ICT by adopting a proper maintenance culture, and a culture of preservation rather than one of negligence or destruction of ICT facilities, equipment, and devices in their vicinities. This maximises the benefits of ERT for their uninterrupted higher educational needs even during and after COVID-19 lockdown.

\subsubsection{Socioeconomic Factor}

Several students from poor socio-economic backgrounds have unfavourable learning environments. They are surrounded by negative influences from peers, places of work and communities that do not value education (Iiyambo and Geduld, 2019). The socioeconomic factor emphasises the general safety and cost-effective availability of ICT facilities and amenities through government deregulation and protection of their right of acquisition and maintenance for IHL and scholars within the state (Latif et al., 2017). This ensures their commercial (surplus but valuable) availability in these IHL at a competitively affordable cost to enable each scholar fair and full access to the service, irrespective of their social strata, race, or income level. To achieve this, subsidisation at both national and 
institutional levels may be required to bridge the ICT divergence for those IHL (and students) who may not afford to procure for or service their ICT needs for effective ERT.

\subsubsection{Geographical Factor}

The geographical factor encompasses each locality within the state with its organic and inorganic physiognomies, including the composition, description, and distribution of both natural and human resources. Physical population distributions, for instance, cause the demand and supply interplay for ICT facilities and amenities, just as urbanisation endears physical infrastructural development (Saghir and Santoro, 2018). Similarly, the topographies where these populations settle (temporary or permanently), also determine the equipment or amenities most convenient and cost-effective for the users, as well as the maintenance of such equipment or amenities. Put differently, people who reside in distant locations from the city will have limited access to quality ICT services, with ripple effects on their educational activities powered by ICT. In the same vein, students that stay far away from their institutions where most ICT installations and equipment are built often experience challenges accessing ICT networks.

\subsubsection{The Disciplinary Nature of Certain Courses or Study Programmes}

The COVID-19 outbreak necessitated the adoption of strict physical restrictions and socioeconomic prohibitions, which render using the traditional model of delivering curricular content in IHL risky on health and safety grounds. While ERT is currently the best practice, the disciplinary nature of some courses or study programmes makes it unsuitable for their curricula contents and instructional materials to be delivered online (Dutton and Mohapatra, 2020). Courses in fields, such as medical and pharmaceutical sciences, engineering and technology (software and hardware), agriculture, environmental sciences, law, accounting and additional fields of learning, require complementary efforts from responsible authorities, establishing 'virtual centres' at public and quasi-public libraries and research centres nationwide. This would meet the virtual learning needs of each scholar at proximate ease (Sikora et al., 2020). Additionally, more professionally practical sessions may be conducted within selected public/private companies and establishments where distinct and enumerated learning parties or groups would assemble on schedule for their virtual learning.

\section{Conclusion}

The current state of the COVID-19 pandemic and responses to manage the pandemic, such as national lockdown and the prolonged restrictions on full human and institutional functioning thereof, testify that ICT has a prolonged mission in human evolution. This is because our growth and advancement on this planet are tied to our knowledge or skill acquisition capacity as living organisms. Further, our capacity to use those skills and knowledge in transforming our lives in the environments is important. This capacity to acquire knowledge and skills became a topical concern during the recent COVID-19 induced lockdown when traditional means of knowledge and skills dissemination are rendered ineffective.

With a drastic decline in both teachers' and students' cumulative teaching and learning processes, the focus rapidly switched from studies to survival. In as much as the COVID-19 lockdown endures, with certain restrictions imposed on South Africa's higher education sector, the need to refocus on remote or distant education re-emerged as the only hope in seeking to salvage the current academic year to avoid the greater challenge of students' mental dormancy. ICT efficacy is just as imperatively indispensable.

From the foregoing, ERT is the most sustainable option amidst COVID-19 lockdown. Overcoming the attendant challenges to maximise the benefits of ERT depends on our capacity to deal with certain overbearing factors, such as the technological (ICT) base, political and administrative climate, and cultural, psycho-cultural, socioeconomic, and geographical factors. These factors interplay at national, institutional, and individual levels. South Africa must broaden its technological base by employing appropriate infrastructure and facilities for ICT. Further, there is a need to implement ICT-friendly policies. These must be accompanied by good administrative practice and compliant ethos and philosophy that secure surplus availability of technological infrastructures and devices in the country, easily acquired at an affordable cost to most citizens.

Institutions of higher learning in South Africa must acquire suitable ICT equipment and facilities, develop rules and regulations for their availability and adequate maintenance, and promote technologically compliant ethics within the institutions, provide easy access for students and academics at an affordable and fixed (secure) cost in safe, conducive, and unrestricted environments. Students must be able to acquire hi-tech gadgets or equipment supporting their ICT needs and afford to maintain them. An appropriate ICT-compliant attitude for safe, secure, and environmentally friendly use of these technological devices for their tuition needs must be cultivated. Students must 
be provided with unrestricted access to ICT networks, irrespective of the time of use or physical location. The profit potentials of ERT at all these levels will be more factual than fictional; the goal is to enhance ease and access. Currently, the revenue is innovation (new and better); the procedure is mechanisation (computerisation or modernisation). This should lead to unlimited efficiency.

\section{References}

Achhnani, B. M. (2019). A discussion on mutual expectations and contributions of different stakeholders in higher education. Journal of Management Research and Analysis, 6(3), 132-136. http://doi.org/10.18231/j.jmra.2019.026

Adedoyin, O. B., \& Soykan, E. (2020). Covid-19 pandemic and online learning: the challenges and opportunities. Interactive Learning Environments, 1-13. https://doi.org/10.1080/10494820.2020.1813180

Aguliera, E., \& Nightengale-Lee, B. (2020). Emergency remote teaching across urban and rural contexts: perspectives on educational equity, Information and Learning Sciences, Vol. 121 No. 5/6, 471-478. https://doi.org/10.1108/ILS-04-2020-0100

Asongu, S. A., \& Le Roux, S. (2017). Enhancing ICT for inclusive human development in Sub-Saharan Africa, Technological Forecasting and Social Change, Vol. 118, 44-54. https://doi.org/10.1016/j.techfore.2017.01.026

Blessinger, P., \& Bliss, T. J. (2016). Introduction to open education: Towards a human rights theory, Open Education: International Perspectives in High Education. Cambridge, Reino Unido, Openbook Publishers, 11-30. https://doi.org/10.11647/OBP.0103.01

Bozkurt, A., \& Sharma, R. C. (2020). Emergency remote teaching in a time of global crisis due to CoronaVirus pandemic. Asian Journal of Distance Education: Vol. 15 No.1, i-vi.

Brammer, S., \& Clark, T. (2020). COVID-19 and Management Education: Reflections on Challenges, Opportunities, and Potential Futures, British Journal of Management, Vol. 31 No. 3, 453-456. https://doi.org/10.1111/1467-8551.12425

Burde, D., Kapit-Spitalny, A., Wahl, R., \& Guven, O. (2011). Education and Conflict Mitigation: What the aid workers say? USAID, 1-60.

Burde, D., Kapit, A., Wahl, R. L., Guven, O., \& Skarpeteig, M. I. (2017). Education in emergencies: A review of theory and research, Review of Educational Research, Vol. 87 No.3, 619-658. https://doi.org/10.3102/0034654316671594

Corrigan, T. (2020). Africa's ICT Infrastructure: Its Present and Prospects. https://media.africaportal.org/documents/Policy-Briefing-197-corrigan.pdf (accessed 21 October 2020).

Czerniewicz, L. (2020). What we learnt from "going online" during University shutdowns in South Africa. Retrieved from http://philonedtech.com/what-we-learnt-from-going-online-during-university-shutdowns-in-south-africa/ (accessed 22 July 2020).

Czerniewicz, L., Agherdien, N., Badenhorst, J., Belluigi, D., Chambers, T., Chili, M., de Villiers, M., Felix, A., Gachago, D., Gokhale, C., \& Ivala, E. (2020). A Wake-Up Call: Equity, Inequality and Covid-19 Emergency Remote Teaching and Learning. Postdigital Science and Education, 2(3), 946-967. https://doi.org/10.1007/s42438-020-00187-4

Gallagher, M. (2019). Artificial intelligence and the mobilities of inclusion: the accumulated advantages of 5G networks and surfacing outliers. In Artificial Intelligence and Inclusive Education (179-194). Springer, Singapore. https://doi.org/10.1007/978-981-13-8161-4_11

Gillies, D. (2015). Human capital, education, and sustainability. Retrieved from https://revistas.rcaap.pt/sisyphus/article/view/6546 (accessed 28 July 2020).

Harms, E., Hussain, S., Newell, S., Piot, C., Schein, L., Shneiderman, S., Turner, T. S., Zhang, J., Harms, E., Hussain, S., \& Newell, S. (2014). Remote and edgy: New takes on old anthropological themes, HAU: Journal of Ethnographic Theory, Vol. 4 No.1, 361-381. https://doi.org/10.14318/hau4.1.020

Hodges, C., Moore, S., Lockee, B., Trust, T., \& Bond, A. (2020). The difference between emergency remote teaching and online learning, Educause Review, 27.

Ifenthaler, D., \& Yau, J. Y. K. (2019). Higher education stakeholders' views on learning analytics policy recommendations for supporting study success. International Journal of Learning Analytics and Artificial 
Intelligence for Education (iJAI), 1(1), 28-42. https://doi.org/10.3991/ijai.v1i1.10978

Karalis, T. (2020). Planning and evaluation during educational disruption: lessons learned from COVID-19 pandemic for treatment of emergencies in education, European Journal of Education Studies, Vol.7 No.4, 125-142.

Latif, Z., Xin, W., Khan, D., Iqbal, K., Pathan, Z. H., Salam, S., \& Jan, N. (2017). ICT and sustainable development in South Asian countries, Human Systems Management, Vol. $36 \quad$ No.4, 353-362. https://doi.org/10.3233/HSM-17166

Iiyambo, S., \& Geduld, B. (2019). Perceptions of Namibian College of Open Learning learners' self-regulated learning skills, Progressio, Vol. 41 No.1, 1-18. https://doi.org/10.25159/0256-8853/4152

McKinsey Global Institute. (2017). Research reports. Retrieved from www.mckinsey.com/mgi (Access August 2020).

Nevado Peña, D., López Ruiz, V. R., \& Alfaro Navarro, J. L. (2020). An analysis of the key role of human and technological development in the smart specialization of smart European regions. Information Technology for Development, 26(4),728-741. https://doi.org/10.1080/02681102.2019.1704675

Patton, L. D. (2016). Disrupting postsecondary prose: Toward a critical race theory of higher education, Urban Education, Vol. 51 No. 3, 315-342. https://doi.org/10.1177/0042085915602542

Power, E., Hughes, S., Cotter, D., \& Cannon, M. (2020). Youth Mental Health in the time of COVID-19, Irish Journal of Psychological Medicine, 1-15. https://doi.org/10.1017/ipm.2020.84

Saghir, J., \& Santoro, J. (2018). Urbanization in Sub-Saharan Africa, Center for Strategic \& International Studies Report, Washington, DC, USA. Retrieved from www.csis.org. (accessed 14 August 2020).

Savani, K., Rattan, A., \& Dweck, C. S. (2017). Is education a fundamental right? People's lay theories about intellectual potential drive their positions on education, Personality and Social Psychology Bulletin, Vol. 43 No. 9, 1284-1295. https://doi.org/10.1177/0146167217711935

Shulman, B. (2020). Minister of Communications and Digital Technology Stella Ndabeni-Abrahams has gazetted a new policy on the deployment of communications networks in South Africa. Retrieved from http://dearsouthafrica.co.za (10 August 2020).

Sinclair, M. (2002). Planning education in and after emergencies. Paris: UNESCO, International Institute for Educational Planning. Retrieved from http://ineeassets.s3.amazonaws.com/resources/Planning_Education_in_and_after_Emergencies.pdf (10 August 2020).

Toquero, C. M., \& Talidong, K. J. (2020). Webinar Technology: Developing Teacher Training Programs for Emergency Remote Teaching amid COVID-19. Interdisciplinary Journal of Virtual Learning in Medical Sciences, 11(3), 200-203.

Tsabedze, V., \& Ngoepe, M. (2020). A Framework for Archives and Records Management Education in an Open Distance E-Learning Environment in eSwatini. Education for Information, 36(2),157-175. https://doi.org/10.3233/EFI-190294

Sikora, A., Irby, S. M., Hall, B. L., Mills, S. A., Koeppe, J. R., Pikaart, M. J., Wilner, S. E, Craig, P. A., \& Roberts, R. (2020). Responses to the COVID-19 Pandemic by the Biochemistry Authentic Scientific Inquiry Lab (BASIL) CURE Consortium: Reflections and a Case Study on the Switch to Remote Learning. Journal of Chemical Education, 97(9), 3455-3462. https://doi.org/10.1021/acs.jchemed.0c00729

Strauss, V. (2013). Nelson Mandela on the Power of Education. Retrieved from https://www.washingtonpost.com/news/answersheet/wp/2013/12/05/nelson-mandelas-famous-quote-on-educati on (10 August 2020). United Nations. General Assembly (1949). Universal declaration of human rights (Vol. 3381). Department of State, United States of America.

Whalen, J. (2020). Should Teachers Be Trained in Emergency Remote Teaching? Lessons Learned from the COVID-19 Pandemic, Journal of Technology and Teacher Education, Vol. 28 No.2, 189-199.

\section{Copyrights}

Copyright for this article is retained by the author(s), with first publication rights granted to the journal.

This is an open-access article distributed under the terms and conditions of the Creative Commons Attribution license (http://creativecommons.org/licenses/by/4.0/). 